\title{
When Are Endovascular and Open Bypass Treatments Preferred for Femoropopliteal Occlusive Disease?
}

\author{
Ali F. AbuRahma, MD
}

Several meta-analyses and multicenter trials have shown that chronic limb ischemia did not occur for up to 5 years in $50 \%-70 \%$ of patients who underwent saphenous vein grafts, with limb salvage and perioperative mortality rates of $>80 \%$ and $3 \%$, respectively. However, open surgical bypass can have limitations, including postoperative morbidity/ wound complications of $10 \%-20 \%$ and prolonged length of hospital stay and outpatient care. Several studies have analyzed clinical outcomes for patients with critical limb ischemia treated with endovascular therapies, but they have been mainly retrospective with significant heterogeneity or were single center. Only few randomized trials have compared surgical vs. endovascular therapy. These included the Bypass vs. Angioplasty in Severe Ischemia of the Leg (BASIL) trial, with no differences found in amputation-free or overall survival rates at 1 year; however, late outcomes favored the surgical group. The Bypass or Angioplasty in Severe Intermittent Claudication (BASIC) trial concluded that the 1 -year patency rates were $82 \%$ and $43 \%$ for bypass and angioplasty, respectively. The BEST Endovascular vs. Best Surgical Therapy in Patients with Critical Limb Ischemia (BEST-CLI) trial is currently enrolling patients. This review analyzed studies comparing open vs. endovascular therapy in patients with femoropopliteal disease. (This is a review article based on the invited lecture of the 45th Annual Meeting of Japanese Society for Vascular Surgery.)

Department of Surgery, West Virginia University, Charleston, West Virginia, USA

Received: January 4, 2018; Accepted: January 4, 2018

Corresponding author: Ali F. AbuRahma, MD. Department of Surgery, West Virginia University, 3110 MacCorkle Ave., SE, Charleston, West Virginia 25304, USA

Tel: +1-304-388-4887, Fax: +1-304-388-4879

E-mail: ali.aburahma@camc.org

This is a review article based on the invited lecture of the 45th Annual Meeting of Japanese Society for Vascular Surgery.

(cc) BY-NC-SA (02018 The Editorial Committee of Annals of Vascular Diseases. This article is distributed under the terms of the Creative Commons Attribution License, which permits use, distribution, and reproduction in any medium, provided the credit of the original work, a link to the license, and indication of any change are properly given, and the original work is not used for commercial purposes. Remixed or transformed contributions must be distributed under the same license as the original.
Keywords: endovascular vs. open bypass, femoropopliteal disease, endovascular treatment for PVD, open repair for PVD

Peripheral arterial disease (PAD) is a steadily increasing global epidemic that affected more than 200 million patients worldwide in 2010.1) More than three billion dollars is spent annually in the United States on healthcare for this disease, surpassing the amount spent on treating cardiovascular diseases. ${ }^{2)}$ A significant number of patients with PAD are asymptomatic; however, patients with intermittent claudication usually experience a limb loss rate of $<5 \%$ over 5 years. Meanwhile, patients with critical limb ischemia (CLI) have a 1-year mortality and major amputation rates of $25 \%$ and $25 \%$, respectively. ${ }^{3)}$ Barani reported a $25 \%$ mortality rate in hospitalized patients, primarily from cardiovascular disease $(74 \%) .{ }^{4)}$ Therefore, when revascularization is needed in patients with claudication, informed discussion regarding outcomes is important, so that expectations regarding patency and need for reintervention are considered.

Traditionally, femoropopliteal disease has been treated with open surgery (femoropopliteal bypass) over the last four to five decades with favorable 5-year patency rate when saphenous vein (ASV) grafts are used. Several metaanalyses and multicenter trials have shown that CLI did not occur for up to 5 years in $50 \%-70 \%$ of patients who underwent ASV grafting to tibial or pedal targets, with limb salvage and perioperative mortality rates of $>80 \%$ and $3 \%$, respectively. ${ }^{5)}$

A large retrospective study of 467 bypass grafts from 2004 to 2012 compared outcomes for ASV and polytetrafluoroethylene (PTFE) grafts. During the 5-year followup, the patency rate with ASV was better than with PTFE grafts $(82 \%$ vs. $\left.26 \%, \mathrm{p}<0.05) .{ }^{6}\right)$ Surgical bypass with PTFE should therefore be limited to patients with no other revascularization option. Meanwhile, the operative mortality is highly variable, which can range from $1.3 \%$ to $6.3 \%$, which largely depends on cardiovascular risk, and should be considered preoperatively.

Open surgical bypass can have important limitations, 
including postoperative morbidity/wound complication rate of $10 \%-20 \%$, prolonged length of hospital stay and outpatient care, additional procedures, and patient discomfort. However, good quality venous conduit may not be available $(20 \%)$. De novo stenosis in vein graft conduit may also occur in $30 \%-40 \%$ of patients in the first 2 years, which may necessitate graft surveillance or reintervention. Moreover, other systemic complications can occur, such as cardiac, pulmonary, and renal complications. ${ }^{5)}$

Meanwhile, several studies analyzing clinical outcomes of patients with CLI treated with endovascular therapies have largely been retrospective with significant heterogeneity or single center. The OLIVE registry, a recent multicenter prospective study, analyzed the outcomes of endovascular treatment for infrainguinal arterial disease with CLI. The results of 314 patients with CLI who underwent endovascular therapy had a 12-month amputationfree survival of $74 \%$, whereas $34 \%$ of patients required reinterventions (endovascular, $31.7 \%$ and bypass surgery, $2.6 \%) .{ }^{7)}$ These data are encouraging in that even in these high-risk patients with CLI $(71 \%$ diabetes mellitus and $52 \%$ hemodialysis) and patients with severe anatomic disease $(42 \%$ below the knee lesions and $>50 \%$ TASC types $\mathrm{C}$ and $\mathrm{D}$ ), endovascular treatment results in $>70 \%$ amputation-free survival.7)

\section{Bypass vs. Endovascular Treatment}

A direct comparison of endovascular therapy and open surgery is generally limited due to variations in vascular anatomy and enrollment in comparative trials is difficult. Patients treated with endovascular therapy usually present with intermittent claudication, whereas patients who undergo surgery usually have CLI. Patients with CLI have higher periprocedural morbidity and mortality rates, diffuse arterial disease, and worse tibial runoff status. Thus, the outcome for surgery in patients would be significantly worse. Furthermore, only few superficial femoral artery (SFA) occlusions are included in endovascular trials. In a series of 100 potential patients for randomized controlled trials, only $4 \%$ were eligible for comparison of PTFE femoropopliteal bypass with endovascular treatment. ${ }^{8)}$

A systematic review meta-analysis of observational studies between 1995 and 2012 showed that no difference was found in mortality, amputation, or amputation-free survival at 2 years. Femoropopliteal bypass using vein grafts have been shown to have better patency rate than PTFE grafts. ${ }^{9 !}$

\section{Randomized Trials of Surgical vs. Endovascular Therapy \\ Bypass vs. Angioplasty in Severe Ischemia of the Leg (BASIL) trial}

This study included 452 patients with CLI that were randomized to surgery or percutaneous transluminal angioplasty (PTA) and followed for up to 5 years. Both ASV $(75 \%)$ and synthetic grafts were used, with the majority being placed in the femoropopliteal segment. The 30-day mortality rates were $5 \%$ and $3 \%$ for surgery and PTA, respectively. The morbidity rate was significantly higher in the surgery group due to wound complications and myocardial infarctions. A cost analysis also favored the endovascular approach. No differences were found in amputation-free survival or overall survival rates at 1 year; however, late outcomes favored the surgical group. The failed endovascular therapy group requiring surgery had lower amputation-free survival rates. This study had some limitations, including suboptimal medical treatment, lack of revascularization patency endpoints, and limited endovascular techniques (only PTA). This trial concluded that bypass using veins offers a better late outcome. Bypass was the preferred treatment for patients with a 2-year or longer life expectancy (70\% of cohort). Prosthetic bypass was associated with poor results; therefore, angioplasty may be preferred in patients who lack adequate vein conduit. Similar conclusions were made by the American College of Cardiology Foundation/American Heart Association. ${ }^{10)}$

\section{BASIL-2 and BASIL-3 trials}

The United Kingdom National Institute for Health Research Health Technology Assessment-funded BASIL-2 and BASIL-3 trials, led by Andrew Bradbury at the Birmingham Clinical Trials Unit (BCTU; University of Birmingham, UK) are complementary randomized controlled trials that will provide further Level 1 evidence regarding the surgical and endovascular treatment of severe limb ischemia due to infra- and femoropopliteal diseases, respectively.

Since the BASIL-1 report, drug-coated balloons and drug-eluting stents have become widely available, and this has led interventionalists to argue for a "best endovascular treatment" strategy for almost all patients with severe limb ischemia.

The National Institute for Health and Care Excellence (NICE) found the results of BASIL-1 more difficult to interpret with regard to treatment of infrapopliteal disease because only approximately $25 \%$ of the cohort of 452 patients had an infrapopliteal bypass or intervention. There remains, therefore, considerable uncertainty as to whether patients presenting with severe limb ischemia due 
to infrapopliteal disease are best served by endovascular treatment or vein bypass.

BASIL-2, which aims to randomize 600 patients with severe limb ischemia secondary to infrapopliteal disease and/or femoropopliteal disease to either the best endovascular treatment first or vein bypass first revascularization strategy.

BASIL-3 will randomize 861 patients with severe limb ischemia secondary to femoropopliteal disease and/or infrapopliteal disease, to plain balloon angioplasty and/or bail-out bare metal stent, drug-coated balloon and/or bare metal stent, and drug-eluting stent.

\section{Bypass or Angioplasty in Severe Intermittent Claudication (BASIC) trial}

This study was performed between 1995 and 1998 and included 56 patients that were randomized from 18 centers and only seven patients were treated with stents. The 1 -year patency rates were $82 \%$ and $43 \%$ for bypass and angioplasty, respectively. ${ }^{11)}$

\section{McQuade trial}

This was a randomized trial of 86 patients (100 limbs) that compared synthetic bypass grafts with PTFE nitinolcovered stent grafts. Patient symptoms included both claudication and limb-threatening ischemia. TASC II A $(\mathrm{n}=18), B(\mathrm{n}=56), \mathrm{C}(\mathrm{n}=11)$, and $\mathrm{D}(\mathrm{n}=15)$ lesions were included. The patients were randomized into one or two treatment groups: the percutaneous treatment group (Group A, $\mathrm{n}=50$ ) with angioplasty and placement of one or more stent grafts or the surgical treatment group (Group B, $\mathrm{n}=50$ ) with a femoral to above-knee popliteal artery bypass using a synthetic conduit (Dacron or PTFE). They were followed for 48 months, including clinical assessment, physical examination, ankle-brachial indices, and color flow duplex sonography at 3, 6, 9, 12, 18, 24,36 , and 48 months. The mean total lesion length of the treated arterial segment in the stent graft group was $25.6 \mathrm{~cm}$. The stent graft group demonstrated a primary patency of $72 \%, 63 \%, 63 \%$, and $59 \%$ with a secondary patency of $83 \%, 74 \%, 74 \%$, and $74 \%$ at $12,24,36$, and 48 months, respectively. The surgical femoral-popliteal group showed a primary patency of $76 \%, 63 \%, 63 \%$, and $58 \%$ with a secondary patency of $86 \%, 76 \%, 76 \%$, and $71 \%$ at $12,24,36$, and 48 months, respectively. No statistical difference was found between the two groups with respect to primary $(\mathrm{p}=0.807)$ or secondary $(\mathrm{p}=0.891)$ patency. They concluded that percutaneous stent grafts exhibit similar primary patency at 4-year follow-up compared with conventional femoral-popliteal artery bypass grafting with synthetic conduit. ${ }^{12)}$ These trials are summarized in Table 1.

\section{PREVENT III and BASIL trials}

The Society for Vascular Surgery recently combined data from the BASIL and PREVENT III trials (only vein bypass grafts) to develop objective goals in patients with CLI with a perioperative (30-day) mortality rate of $3 \%$, major adverse cardiovascular event rate of $6 \%$, graft occlusion rate of $5 \%$, and amputation rate of $2 \%{ }^{13}$ ) (Table 2 ).

Table 1 Randomized trials comparing endovascular treatment to surgery for femoral-popliteal disease

\begin{tabular}{cccccc}
\hline Trial & Patients $(\mathrm{n})$ & Indication & Endovascular treatment & Bypass location/conduit & Outcome \\
\hline BASIL & 452 & Chronic limb ischemia & Balloon angioplasty & $\begin{array}{c}\text { Infrainguinal ASV or } \\
\text { synthetic (minority) }\end{array}$ & Similar rates at 1 year \\
BASIC & 56 & Intermittent claudication & $\begin{array}{c}\text { Balloon angioplasty } \\
\text { with provisional stenting } \\
\text { Covered stent graft }\end{array}$ & Fem-pop synthetic graft & $\begin{array}{c}\text { Similar 2-year patency rate } \\
\text { with surgery at 1 year }\end{array}$ \\
McQuade & 86 & $\begin{array}{c}\text { Intermittent claudication and } \\
\text { chronic limb ischemia }\end{array}$ & Fimer & & \\
\hline
\end{tabular}

Table 2 1-year results of ASV bypass for CLI from recent multicenter prospective trial sources

\begin{tabular}{lccc}
\hline & PREVENT III & BASIL & SVS objective performance goals cohort*** \\
\hline Patients ( $)$ & 1,404 & 186 & 838 \\
Diabetes (\%) & 64 & 42 & 57 \\
Survival (\%) & 84 & 81 & 86 \\
Limb salvage (\%) & 88 & 88 & 89 \\
Amputation-free survival (\%) & 78 & 72 & 77 \\
MALE (\%) & 75 & 80 & 77 \\
Amputation or reintervention (\%)** & 63 & 72 & 64 \\
\hline
\end{tabular}

*Freedom from major adverse limb event at 1 year. ${ }^{* *}$ Freedom from an ipsilateral rerintervention or major amputation at 1 year. *** Conte et al., JVS, 2009. 
Technical factors were speculated to be critical in the short- and long-term success of bypass surgery, wherein vein quality was very important, and single-segment great saphenous veins with a diameter of $\geq 3.5 \mathrm{~mm}$ were optimal conduits for leg bypass. Approximately one half of PREVENT III trial patients had such conduits, which had a 30 -day failure rate of $1.7 \%$, with a secondary patency rate of $87 \%$, and a limb salvage rate of $91 \%$ at 1 year.

The PREVENT III cohort and several large series have found that diabetes mellitus does not adversely affect infrainguinal vein graft patency, in contrast to endovascular treatment. ${ }^{14,15)}$

\section{BEST Endovascular vs. Best Surgical Therapy in Patients with Critical Limb Ischemia (BEST-CLI) trial}

This randomized trial is currently enrolling patients with CLI who are candidates for both open surgery and endovascular therapy. This study will compare the effectiveness of the best available surgery vs. the best available endovascular treatment. ${ }^{16)}$ This multidisciplinary trial, led by Alik Farber (Boston Medical Center, Boston, USA), Matthew Menard (Brigham and Women's Hospital, Boston, USA), and Kenneth Rosenfield (Massachusetts General Hospital, Boston, USA), is currently enrolling patients at 135 sites in the United States and Canada. BEST-CLI both encourages and facilitates specialists who treat CLI at a given trial site to work together for the benefit of patients. The key to successful engagement in the effort is the ability of participating investigators to set aside their individual treatment biases and acknowledge the absence of reliable scientific evidence to support their impulses. This trial is near the halfway mark.

\section{Other Nonrandomized Trials}

Siracuse et al. reviewed all lower extremity bypass procedures from 2001 to 2009 and all PTA and/or stenting performed from 2005 to 2009 for claudication only. They identified 113 bypass grafts and 105 PTA and/or stenting of femoral-popliteal lesions without prior intervention. The bypasses were above and below the knee in $62 \%$ (45\% vein) and $38 \%$ (100\% vein), respectively. The mean age for bypass and PTA and/or stenting patients was 63 and 69 years, respectively $(\mathrm{p}<0.01)$. The mean length of hospital stay was 3.9 vs. 1.2 days $(\mathrm{p}<0.01)$. Bypass grafts were used less for TASC A $(17 \%$ vs. $40 \%, \mathrm{p}<0.01)$ and more for TASC C $(36 \%$ vs. $11 \%, \mathrm{p}<0.01)$ and TASC D $(13 \%$ vs. $3 \%, p<0.01)$ lesions. No significant differences were found in the perioperative $(2 \%$ vs. $0 \%)$ or 3 -year mortality rate $(9 \%$ vs. $8 \%)$. Wound infection was higher with bypass $(16 \%$ vs. $0 \%, \mathrm{p}<0.01)$; however, no grafts were involved. Bypass showed improved freedom from restenosis (73\% vs. $42 \%$ at 3 years; hazard ratio [HR], 0.4 ), symptom recurrence $(70 \%$ and $36 \%$ at 3 years), and freedom from symptoms at last follow-up ( $83 \%$ vs. $49 \%$; HR, 0.18). No difference was found in freedom from reintervention ( $77 \%$ vs. $66 \%$ at 3 years). A multivariable analysis showed that restenosis was predicted by PTA and/or stenting (HR, 2.5) and TASC D (HR, 3.7) lesions. Recurrence of symptoms was similarly predicted by PTA and/or stenting (HR, 3.0) and TASC D lesion (HR, 3.1). Postoperative statin use postoperatively was predictive of patency (HR, 0.6) and freedom from recurrent symptoms (HR, 0.6). They concluded that surgical bypass for the primary treatment of claudication showed improved freedom from restenosis and symptom relief despite treatment of more extensive disease, but it was associated with an increased length of hospital stay and wound infection. Statins improved freedom from restenosis and symptom recurrence overall. ${ }^{17}$

Dosluoglu et al. compared stenting vs. above-the-knee PTFE bypass for TransAtlantic Inter-Society Consensus-II $\mathrm{C}$ and D SFA disease. Consecutive patients who underwent above-the-knee femoropopliteal bypass with PTFE or PTA/S for TASC-II C (PTA/S-C) or D (PTA/S-D) SFA lesions between June 2001 and April 2007 were retrospectively analyzed. In 127 patients, 139 limbs were treated (46 above-the-knee femoropopliteal, 49 PTA/S-C, and $44 \mathrm{PTA} / \mathrm{S}-\mathrm{D})$. The mean occlusion and stented lengths were $9.9 \pm 3.8$ and $24.3 \pm 6.6 \mathrm{~cm}$, and $26.6 \pm 5.5$ and $30.0 \pm 5.2 \mathrm{~cm}$ in PTA/S-C and PTA/S-D, respectively. The technical success rate was $84 \%$ and $100 \%$ in PTA/S-D and other groups, respectively. The mean follow-up was 26.4 months. The 12 - and 24-month primary patency was $83 \% \pm 6 \%$ and $80 \% \pm 7 \%$ for PTA/S-C, $54 \% \pm 8 \%$ and $28 \% \pm 12 \%$ for PTA/S-D, and $81 \% \pm 6 \%$ and $75 \% \pm 7 \%$ for above-the-knee femoropopliteal bypass $(\mathrm{p}<0.001$ PTA/S-D vs. PTA/S-C and above-the-knee femoropopliteal bypass). Secondary patency was $98 \% \pm 3 \%$ and $98 \% \pm 3 \%$ for PTA/S-C, $72 \% \pm 7 \%$ and $54 \% \pm 11 \%$ for PTA/S-D, and $81 \% \pm 6 \%$ and $78 \% \pm 7 \%$ for abovethe-knee femoropopliteal bypass. Secondary patency in PTA/S-C was significantly better than that in the abovethe-knee femoropopliteal bypass $(\mathrm{p}=0.003)$ and PTA/S-D groups $(\mathrm{p}<0.001)$. The difference in above-the-knee femoropopliteal bypass was marginally better than that in PTA/S-D $(\mathrm{p}=0.064)$. They concluded that PTA/S-C lesions had a superior midterm patency than above-theknee femoropopliteal bypass using PTFE, and abovethe-knee femoropopliteal bypass with PTFE has a better primary patency than PTA/S-D. The TASC-II recommendations should be modified to recommend treatment of SFA TASC-II C lesions by PTA/S rather than PTFE bypass for all patients. PTA/S-D lesions should only be considered in high-risk patients who cannot tolerate a bypass proce- 


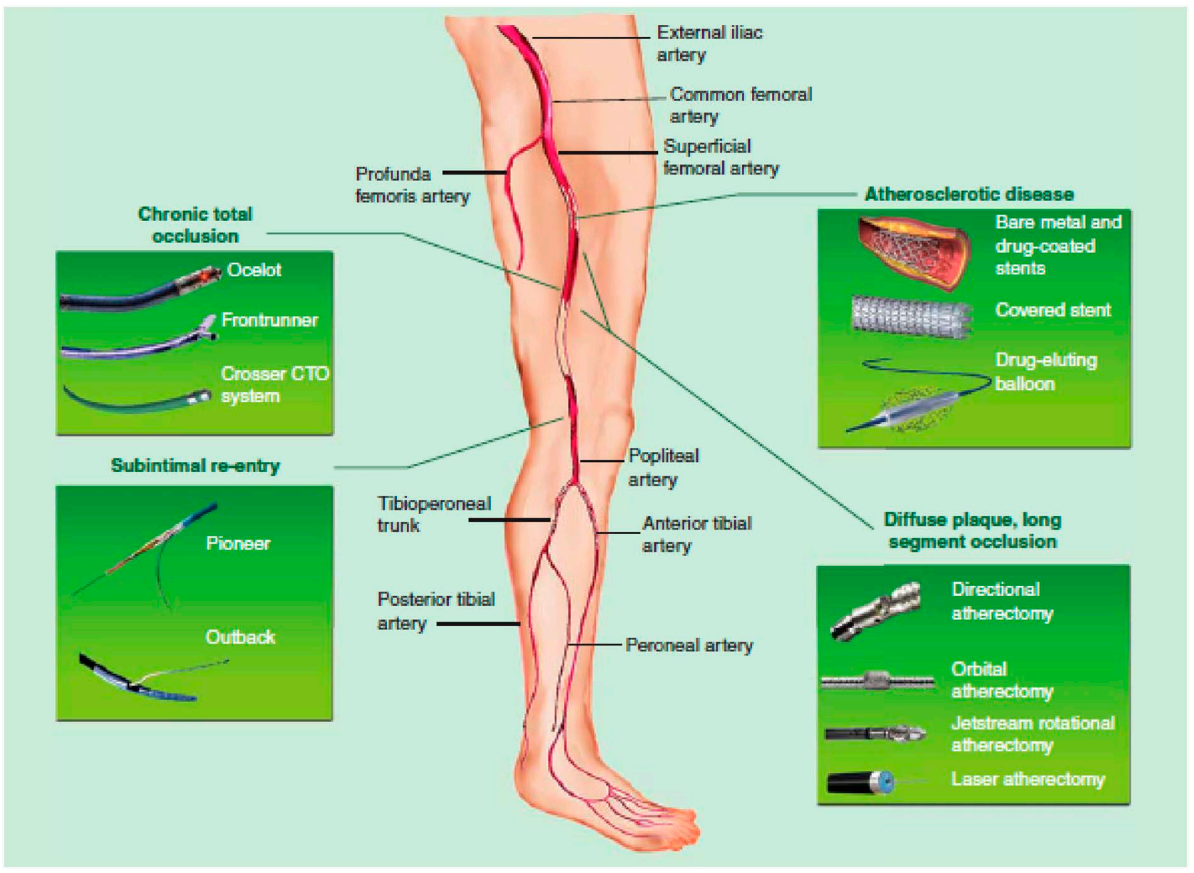

Fig. 1 Current therapeutic endovascular options for the treatment of femoropopliteal occlusive disease.

dure using PTFE. ${ }^{18)}$

\section{Contemporary Endovascular Treatment for Femoral-Popliteal Disease}

Current endovascular treatment includes PTA/stenting, cutting PTA, atherectomy, covered stents (stent grafts), drug-coated balloons, drug-coated stents, brachytherapy, and cryoplasty (Fig. 1). The following is a review of each modality.

\section{Angioplasty/Stenting}

PTA for CLI can achieve a 5-year limb salvage rate of $89 \%$, similar to earlier reported values with surgical revascularization, which ranged from $70 \%$ to $80 \% .{ }^{19}$ Although the primary patency after PTA for CLI may be low, the limb salvage rate is quite high. ${ }^{19,20)}$

The Society of Cardiovascular and Interventional Radiology Transluminal Angioplasty and Revascularization (STAR) registry ${ }^{21}$ is a database of patients who underwent conventional angioplasty or other percutaneous intervention for lower extremity PAD performed at seven hospitals over a 3-year period. Patients were followed for 5 years.

A total of 219 limbs in 205 patients were analyzed: $79 \%$ with stenoses and $11 \%$ with occlusions were treated and $6 \%$ had concurrent stenosis and occlusion. The mean lesion length was 3.8 and $4.7 \mathrm{~cm}$ for stenotic lesions and occlusions, respectively. The technical success rate was $95 \%$. The primary patency rates were $87 \%, 80 \%$, and $69 \%$ at 1,2 , and 3 years, respectively. Diabetes and poor runoff scores were associated with decreased patency rates. The type of lesion (stenosis vs. occlusion) or the complexity of the lesion (classified according to the AHA task force classification categories $1-4$ ) seemed to have no effect on patency; however, the number of Class 4 lesions was very limited.

A meta-analysis of 19 studies (1993-2000), which included 923 PTAs wherein patients were divided into four categories by combinations of their lesion type (occlusion vs. stenosis) and symptoms (CLI vs. claudication). The lesion length was $<10 \mathrm{~cm}$ in all but one study. The combined 3-year primary patency rates were $61 \%$ for patients with stenosis and claudication, $48 \%$ for occlusion and claudication, $43 \%$ for stenosis and CLI, and $30 \%$ for occlusion and CLI. These rates were statistically similar to those for primary stenting with regard to patients with claudication and stenosis, but they were inferior with respect to stenting for occlusion/CLI. ${ }^{22)}$

Met et al. ${ }^{23)}$ conducted a systematic review of 23 cohort studies (1966-2007; 1,549 patients) to review outcomes using the subintimal angioplasty technique for infrainguinal occlusive disease. They were unable to perform a meta-analysis because of the heterogeneity between the studies. Technical success ranged from $80 \%$ to $90 \%$, with 1 -year clinical success rates of $50 \%-70 \%$. Primary patency rates were approximately $50 \%$ at 1 year, and limb 
salvage rates were $80 \%-90 \%$. Therefore, the authors concluded that subintimal angioplasty was a useful technique for difficult lesions, particularly for limb salvage in CLI, and they viewed this technique as a reasonable method of treating patients with CLI and contraindications to surgical treatment.

The use of stents was initially advanced to improve long-term patency rates from PTA, particularly in treating longer segment disease $(>10 \mathrm{~cm})$, wherein angioplasty outcomes remained poor. Stenting may improve the initial angiographic outcome, reduce elastic recoil, and provide a scaffold in the setting of dissection. The initial study results were disappointing, with several randomized trials failing to show any benefit of stent placement over PTA alone. These findings led to the recommendation for stenting only in the setting of a suboptimal technical result following balloon angioplasty. However, these studies were conducted using balloon-expandable stainless steel stents, and more recent studies using self-expanding nitinol stents have shown significantly better results.

Three major randomized trials comparing primary nitinol stent placement with stent-assisted angioplasty have been reported and showed differing results:

The femoral artery stenting trial analyzed outcomes with stand-alone PTA vs. primary stenting with a single self-expanding nitinol stent. Only single short-segment lesions of $<10 \mathrm{~cm}$ were included, with a mean lesion length of $45 \mathrm{~mm}$ for both groups. A total of 123 patients were assigned to primary stenting, and 121 patients were randomized to PTA alone. Technical success was achieved in $79 \%$ and $95 \%$ of the PTA and stenting groups, respectively. Restenosis rates at 1 year, determined by ultrasound, were not statistically different between the two groups (39\% in PTA and 32\% in stent). Maximal walking distance was slightly improved in the stenting group, but no difference was found in resting ankle-brachial index or change in Rutherford class. Stent fractures were also assessed due to concern regarding nitinol stent fracture risk and possible subsequent increase in restenosis. Stent fractures were found in $12 \%$ of patients in the trial, with no statistically significant increase in restenosis associated with the presence of fractures.

The RESILIENT trial is a prospective multicenter trial of 234 patients that compared bare nitinol stents (LifeStent, CR Bard, New Jersey, USA) in patients with a mean lesion length of $7.1 \mathrm{~cm}$ with PTA patients with a mean lesion length of $6.4 \mathrm{~cm}$. Forty percent of patients with PTA had bailout stent for $>30 \%$ residual stenosis or dissection. This study suggested a statistical advantage of improved patency with stent over PTA alone in femoral-popliteal lesions. The technical success rate was better with stenting ( $96 \%$ vs. $84 \%$ ). Freedom from target lesion revascularization in the stent group was significantly bet- ter than that in the PTA group at 6 and 12 months: $94.2 \%$ and $81.3 \%$ in the stent group, respectively, vs. $47.4 \%$ and $36.7 \%$ in the PTA group, respectively. The stent fracture rate was $3 \%$ at 12 months and was not associated with any adverse clinical sequelae. The study showed continued advantages of bare metal stents vs. PTA at 3-year follow up. The authors concluded that primary stent placement with a self-expanding nitinol stent is superior to treatment with PTA alone for moderate-length lesions. ${ }^{24,25)}$

The ABSOLUTE trial (Balloon Angioplasty vs. Stenting with Nitinol Stents in the SFA) included 104 patients with severe intermittent claudication and/or tissue loss (Rutherford classes 3-5), with lesions longer than $30 \mathrm{~mm}$ and at least one patent runoff vessel. Patients were randomized to PTA plus optional stenting or primary stenting with nitinol stents. The mean target lesion length was 112 and $93 \mathrm{~mm}$ for the stent and PTA groups, respectively. Restenosis rates were significantly lower in the primary stenting group at 2 years ( $46 \%$ vs. $69 \%$ ). No difference was found between the two groups with respect to Rutherford class upon follow-up, but a trend was found toward improved walking capacity and resting ankle-brachial index in the stent group. Overall, reintervention rates were lower in the primary stent group. ${ }^{24,25)}$

Current evidence supports a specific endovascular strategy. With the advances in stent technology, nitinol self-expanding stents have ultimately led to improved results for primary stenting in SFA lesions. The use of newer generation nitinol stents in SFA disease has demonstrated reduced restenosis compared with standard PTA. ${ }^{26,27)}$ Schillinger et al. analyzed 104 patients with symptomatic PAD (12\% had CLI) and SFA disease. They were randomly assigned to either primary stenting or angioplasty with bailout stenting for suboptimal angioplasty results. At 6 months, the angiographic restenosis was $24 \%$ and $43 \%$ in the stent and angioplasty groups, respectively $(\mathrm{p}=0.05)$. This trend became significant at 12 months, at which point restenosis by duplex ultrasound was $37 \%$ and $63 \%$ in the stent and PTA groups, respectively $\left.(p=0.01) .{ }^{26}\right)$ This study showed statistically superior patency and physical function in $10-12 \mathrm{~cm}$ mean lesion lengths with nitinol stents vs. PTA alone.

\section{Supera stent}

Recent midterm results claim high patency rates in the treatment of long lesions with a 1 -year patency of $91 \%$ with the interwoven nitinol stent (Supera). ${ }^{28)}$

Montero-Baker et al. analyzed the outcome of endovascular therapy for femoropopliteal disease with the Supera stent. A total of 305 Supera stents were implanted in 147 patients. The mean follow-up was 12.7 months. Most patients had CLI with tissue loss (38\%) or rest pain $(29 \%)$. Primary, assisted primary, and secondary patency 
rates at 12 months by duplex ultrasound imaging were $90 \%, 91 \%$, and $93 \%$, respectively, with a mean lesion length of $184.5 \pm 131.80 \mathrm{~mm}$ and a mean stented length of $197.5 \pm 113.65 \mathrm{~mm}$. Seventeen patients experienced an event requiring successful reintervention in the stented segment (13 for type I or II restenosis and 4 for type III). Eight major amputations were performed, with five of those having a patent stent at the time of limb sacrifice. The overall mortality rate was $12 \%$ during the study period. No stent fractures were identified. They concluded that stenting of the SFA and popliteal arteries using the Supera stent system seem to be safe and effective. The interwoven stent design may better serve areas under extreme mechanical stress. ${ }^{29)}$

\section{Gore's TIGRIS stent}

A prospective, multicenter, noninferiority, randomized, controlled clinical study was conducted to evaluate the TIGRIS stent. The dual component design of this stent allows natural movement, conformation, and maximum flexibility, which minimizes the risk of fracture. Patients from 33 sites in the United States and three in Europe were randomized 3:1 to treat with TIGRIS or LifeStent (Bard). The mean pretreatment lesion lengths were 107.6 \pm 68.6 and $117.9 \pm 75.4 \mathrm{~mm}$ for TIGRIS and LifeStent, respectively. Occlusive disease was present in $42 \%$ and $37 \%$ of patients with the TIGRIS stent and LifeStent, respectively. Kaplan-Meier estimates at 24 months showed a primary patency rate of $63 \%$ and $67 \%$ for TIGRIS and LifeStent, respectively, and a freedom from target lesion revascularization rate of $77 \%$ and $81 \%$ for TIGRIS and LifeStent, respectively. No stent fractures were noted with the TIGRIS stent vs. 29\% with LifeStent. ${ }^{30)}$

\section{Challenges in stenting SFA/popliteal lesions}

The SFA and popliteal arteries, unlike other arteries, are subject to triplanar intermittent mechanical stresses, including contraction, extension, torsion, flexion, and compression. The efficacy of stents in this location is limited by the fact that they can only deform to a limited extent to stresses exerted on the artery. This lack of flexibility and resistance to stress may induce stent fractures and promote poorer patency. The Femoral Stenting in $\mathrm{Ob}$ structions study found that stent fractures were common in long lesions ( $52 \%$ fractures in $>16 \mathrm{~cm}$ stented length). Significant restenosis $(>50 \%)$ was also seen in $33 \%$ of cases, and complete stent reocclusion was noted in another $34 \%$ of cases. Overall, patients with stent fractures had poorer patency compared with those without stent fractures ( $41 \%$ vs. $84 \%$ at 12 months; $\mathrm{p}<0.0001) .{ }^{31)}$

\section{Cutting Balloon Angioplasty}

Cutting balloon angioplasty was originally developed for coronary arteries and used low-pressure balloon catheters mounted with microsurgical blades or microtomes that cut into luminal vessel during inflation. The cutting balloon by Boston Scientific (Natick, MA, USA) is equipped with four microsurgical blades that are bonded longitudinally to a balloon. The mechanism of action is controlled disruption of the vessel wall, resulting in more controlled dilatation at lower balloon inflation pressures.

A prospective randomized controlled trial of de novo SFA lesions of 43 patients (19\% had CLI) compared cutting balloon angioplasty with conventional angioplasty and showed a restenosis rate of $32 \%$ and $62 \%$ in the PTA and cutting balloon angioplasty groups, respectively, by duplex ultrasound at 6 months $(\mathrm{p}=0.048) .{ }^{32)}$ In a comparison of conventional balloon angioplasty and cutting balloon angioplasty in 36 patients with failing infrainguinal bypass grafts, initial success was better for the cutting balloon cohort, but 1-year primary patency did not differ between the two groups. ${ }^{33)}$ Therefore, cutting balloon angioplasty is not routinely used because of higher costs and inferior results (vs. conventional PTA), but it can be used for in-stent restenosis and diseased arteries in flexion points (common femoral or popliteal artery, stent fracture risk). ${ }^{32)}$ Larger prospective multicenter trials are needed to highlight the role of atherectomy in femoral-popliteal arterial disease.

\section{Atherectomy}

Atherectomy involves debulking or atherosclerotic plaque removal. Current devices for this modality include rotational, directional, orbital, and laser atherectomy. Atherectomy for patients with PAD is currently used as adjunctive/alternative therapy to traditional PTA or stenting. Plaque debulking leads to an immediate increase in lumen size, which should result in reduced stretch injury of the arterial walls. ${ }^{34,35)}$ Atherectomy devices have been evaluated as a potential solution to the long-term primary patency ( $50 \%$ at 3 years) for standard PTA in the femoropopliteal segment.

Directional atherectomy using the Silverhawk (Covidien, Plymouth, MN, USA) catheter shaves off plaque as the atherectomy blade rotates, whereas debris is collected inside a nose cone located at the tip of the catheter. The Silverhawk device can be safely used as an adjunctive tool or as stand-alone therapy, particularly in patients with CLI. ${ }^{36)} \mathrm{A}$ small series evaluating TASC-type C femoropopliteal lesions in CLI showed that atherectomy achieved acceptable early results. One potential complication is embolization although the TALON registry reported a very 
low embolization rate $(0.1 \%) .{ }^{37)}$

The PROTECT study included a single-center prospective registry of 40 patients undergoing infrainguinal intervention of 56 lesions using distal embolic protection both during standard PTA/stenting and during directional atherectomy (Silverhawk device). Macroembolization occurred in $38 \%$ of the PTA/stenting group and $100 \%$ in the Silverhawk group, with debris $\geq 2 \mathrm{~mm}$ in $90 \%$ of the atherectomy group. The DEFINITIVE $\mathrm{Ca}++$ study included 133 patients with 168 moderate to severely calcified femoropopliteal lesions treated with the Silverhawk or Turbohawk (Covidien, Plymouth, MN, USA) and distal embolic protection. They reported a 93\% freedom from major adverse events, which included clinically significant embolization. However, the definitive clinical benefit of atherectomy over PTA was unclear.

In another study, 131 lesions in 84 patients that presented with Rutherford category 2-5 ischemia were treated using the Silverhawk device with a technical success of $86 \%$ of cases with atherectomy alone and in $100 \%$ of cases using additional adjunctive modalities. ${ }^{38)}$ Primary and secondary patency rates were improved in patients who were treated for de novo lesions compared with those treated for restenosis. In another analysis of a prospectively maintained registry, 579 lesions were treated in 275 patients $(63 \%$ CLI) with primary and secondary patency rates of $53 \%$ at 12.5 months and $75 \%$, respectively. The overall limb salvage rate was $93 \%$ at 18 months. ${ }^{39)}$

The Excimer laser (ClirPath, Colorado Springs, CO, USA) uses a 308-nm ultraviolet wavelength and functions by ablating tissue on contact, without causing an increase in temperature in the surrounding tissue. A study evaluated the use of this laser for 411 consecutive procedures in 318 patients with long SFA occlusions and found that the technical success rate was $91 \%$, and the 1 -year secondary patency rate was $71 \% .{ }^{40)}$ In the Laser Angioplasty for Critical Limb Ischemia (LACI) trial, 423 lesions were treated in 145 patients who were poor candidates for surgical revascularization; the reported 6-month limb salvage rate was $93 \%{ }^{41}$ )

The EXCITE (Excimer Laser Atherectomy) trial enrolled patients from 40 United States centers and included patients with a Rutherford class 1-4 target lesion length $\geq 4 \mathrm{~cm}$ and a vessel diameter of $5-7 \mathrm{~mm}$. Patients were randomly divided into excimer laser atherectomy and PTA vs. PTA alone (2:1 ratio). The primary efficacy endpoint was target lesion revascularization at 6-month follow-up, and the primary safety endpoint was a major adverse event (death, amputation, or target lesion revascularization) 30 days postoperatively. The study was stopped at 250 patients due to early efficacy. The mean lesion length was $19.6 \pm 12.0$ vs. $19.3 \pm 11.9 \mathrm{~cm}$. Total occlusion was present in $31 \%$ vs. $37 \%$ of patients. The Excite laser atherectomy with PTA was superior, with a success rate of $94 \%$ vs. $83 \%(p=0.01)$. The freedom from target lesion revascularization at 6 months was $74 \%$ for the Excite laser atherectomy, with PTA vs. 52\% for PTA alone $(\mathrm{p}<0.005)$. The 30-day major adverse event rate was $6 \%$ vs. $21 \%(p<0.001)$. The Excite laser atherectomy with PTA resulted in a $52 \%$ reduction in target lesion revascularization. ${ }^{42)}$

\section{The Determination of Effectiveness of Silverhawk Peripheral Plaque Excision System for Treatment of Infrainguinal Vessels of Lower Extremity (DEFINITIVE LE) study}

This prospective multicenter registry treated 800 patients with directional atherectomy. The 12 -month primary patency rate was $78 \%$ in patients with intermittent claudication. The freedom from major unplanned amputation of the target limb was $95 \%$ in patients with CLI.

Larger prospective multicenter trials are needed to highlight the role of atherectomy in femoral-popliteal arterial disease.

\section{Covered Stents}

Stent grafts using endovascular techniques attempted to duplicate open prosthetic femoropopliteal bypass. The Viabahn stent graft (W L Gore \& Associates, Inc., Flagstaff, AZ, USA) consists of a self-expanding nitinol stent bonded to a graft made of expanded PTFE. They perform well in long segment occlusions and SFA restenosis; however, appropriate sizing and adequate runoff are required for optimal outcome, and dual antiplatelet therapy is also required for at least 6 months.

The VIASTAR trial (Viabahn Endoprosthesis with Propaten Bioactive Surface vs. Bare Nitinol Stent in the Treatment of Long Lesions in SFA Occlusion) studied 141 patients randomized to Viabahn or bare metal stents. The 1 -year patency rate was higher with long lesions $(>20 \mathrm{~cm})$ with covered stents vs. bare metal stents $(71 \%$ vs. $37 \%$, $\mathrm{p}=0.01) .{ }^{43)}$ The Viabahn stent was then modified where the excess graft material was removed, which may have compromised inflow, and heparin was bonded to the stent. This was examined in the VIPER trial for the treatment of SFA occlusion where the primary and secondary patency rates improved to $73 \%$ and $92 \%$, respectively. Stent oversizing was a major factor in lower patency rates. ${ }^{44)}$ Lammer et al. reported that patients with PAD with long femoral-popliteal lesions had significantly improved primary patency rates with covered vs. bare metal stents at 24 months; however, no significant impact was found on clinical outcomes and target lesion revascularizations. ${ }^{45)}$

In the Viabahn vs. Bare Nitinol Stent Trial (VIBRANT trial) that compared long-term outcomes of covered stents 
with bare metal stents in the SFA, 148 patients were randomized to receive self-expanding nitinol vs. Viabahn stents. Although no differences were seen in 3-year primary patency or freedom from target lesion revascularization between the two groups, the Viabahn stents were less likely to fracture. ${ }^{46)}$

\section{Femoropopliteal-Drug-Eluting Balloons and Stents}

Drug-coated angioplasty balloons (DCBs) and drug-eluting stents (DESs) are designed to limit the proliferative, reactionary process of neointimal hyperplasia. Researchers have hypothesized that these technologies would improve the patency rates observed in the femoropopliteal stenting trials, and a number of device-specific trials have been conducted in recent years.

DCBs were developed to improve the durability of PTA, without the potential drawbacks of stents. Although stents are useful in preventing the elastic recoil of arteries after angioplasty, stents have been hypothesize to actually increase neointimal hyperplasia by causing repetitive trauma and increased inflammatory reaction. DCBs are designed to curb neointimal hyperplasia by delivering large doses of anticell proliferation agents directly to the site of vessel injury. ${ }^{47)}$

Paclitaxel is a proven antiproliferative drug that stops cell division and induces apoptosis. The IN.PACT Admiral DCB coating consists of paclitaxel and urea, a carrier molecule. The majority of the paclitaxel-urea matrix is protected within the folds of the balloon as a result of the semi-inflated coating process. When exposed to blood during inflation, the urea hydrates, and releases paclitaxel. Subsequently, the drug transfers into the wall of the artery and migrates through the vessel wall into the media. The IN.PACT Admiral DCB delivers paclitaxel in solid phase, thus establishing reservoirs of drug within the vessel wall. These reservoirs permit sustained drug availability and release and subsequent long-term antiproliferative effect. Paclitaxel is generally present in the arterial wall at 6 months in preclinical studies. ${ }^{47)}$

Several ongoing studies have reported on paclitaxel DCBs in de novo and restenotic femoral-popliteal lesions. Using DCBs to treat in-stent restenosis is preferred over placing additional stents because additional overlapping stents are associated with a higher rate of stent fracture and restenosis. Currently, two DCBs, Lutonix 035 (Bard) and IN.PACT Admiral (Medtronic), were approved for use in the United States.

The majority of clinical trial data on DCBs have predominantly included patients with claudication and lower Rutherford classifications, as opposed to patients with CLI. The THUNDER, FemPac, PACIFIER, and
LEVANT-1 trials ${ }^{47-51)}$ assessed femoropopliteal lesions comparing DCB with standard PTA. More than $90 \%$ of these patients had intermittent claudication with Rutherford class 3 or less. Late lumen loss, target lesion revascularization, and angiographic restenosis significantly favored DCBs in these trials.

\section{Review of Commonly Quoted DCB Trials}

The LEVANT trial (Lutonix Paclitaxel CB [Bard] for Prevention of Femoral-Popliteal Restenosis) randomized 101 patients to Lutonix DCBs or uncoated balloons. A significant increase was found in the primary patency rate at 12 months with the Lutonix $035 \mathrm{DCB}$ vs. plain balloon angioplasty $(74 \%$ vs. $57 \%, \mathrm{p}<0.001)$. At 24 months, major adverse events (death, amputation, target lesion thrombosis/reintervention) were $39 \%$ for DCB and $46 \%$ for patients with uncoated balloon $(\mathrm{p}=0.45) .{ }^{51)}$

The currently ongoing LEVANT-2 trial is a large, international, randomized trial comparing paclitaxel-coated balloon angioplasty (Lutonix, Bard, Tempe, AZ, USA) to standard PTA for femoropopliteal disease. It should be noted that the results of DCBs have not been encouraging for below-the-knee vessels. The IN.PACT DEEP study was halted prematurely because it showed, in contrast to previously mentioned trials, no difference between the IN.PACT Amphirion DCB treatment group and the standard balloon angioplasty control group in any of the study's three primary outcome measures. The study also identified a potential safety signal with a trend toward an increased rate of major amputations in the DCB study arm. ${ }^{52)}$ Similar to the studies of infrapopliteal DESs, the studies involving infrapopliteal DCBs failed to use limb salvage or amputation-free survival as primary endpoints.

Medtronic's IN.PACT SFA trial is a prospective, multicenter, randomized trial wherein 331 patients with intermittent claudication and CLI, secondary to femoral-popliteal PAD, were randomly assigned in a $2: 1$ ratio to treat with DCB (paclitaxel) or PTA. More than $90 \%$ of lesions were de novo, with a mean lesion length of $\geq 8 \mathrm{~cm}$ in both groups. A higher primary patency rate at 12 months in the IN.PACT Admiral DCB group was noted, compared with the PTA group $(82 \%$ vs. $52 \%, \mathrm{p}<0.001)$. The rate of clinically driven target lesion revascularization was $2.4 \%$ and $20.6 \%$ in the DCB and PTA groups, respectively $(\mathrm{p}<0.001)$. No device/procedure-related death or major amputation occurred. ${ }^{53)}$

\section{The IN.PACT Admiral (Medtronic) DCB in drug- eluting balloon (DEB) SFA-long study}

This prospective, multicenter, single-arm study analyzed the outcome of 105 patients in the treatment of long (TASC C and D, $>15 \mathrm{~cm}$ long) femoral-popliteal lesions. 
The mean lesion length was $252 \pm 79 \mathrm{~mm}$, and $50 \%$ of patients had moderate-to-severe calcified lesions, and $50 \%$ had total occlusion. The primary patency rate at 24 months was $70 \%$ ( $74 \%$ for stenotic lesions vs. $68 \%$ for occlusions). It also showed no significant difference in patency with long $(\leq 25 \mathrm{~cm})$ vs. very long $(>25 \mathrm{~cm})$ lesions at 24 months $(75 \%$ vs. $66 \%, p=0.25)$. The freedom from target lesion revascularization was $85 \% .{ }^{54)}$

\section{IN.PACT global study (Medtronic's IN.PACT Admiral DCB)}

This was an independently adjudicated/monitored multicenter, international, prospective, single-arm study of the treatment of 1,406 real-world patients with symptomatic femoral-popliteal lesions. The mean lesion length was $12 \pm 10 \mathrm{~cm}$. In-stent restenosis, total occlusion, and calcified lesions were present in $18 \%, 36 \%$, and $69 \%$, respectively. The freedom from clinically driven target lesion revascularization at 12 months was $93 \%$. The freedom from major target limb amputation and clinically driven target lesion revascularization was $92 \%$. The major target limb amputation and thrombosis rates at 12 months were $0.2 \%$ and $3 \%$, respectively. ${ }^{55)}$

The THUNDER trial followed 154 patients who were treated with DCBs, angioplasty with paclitaxel in contrast medium, or no paclitaxel (control group) for 5 years. Target lesion revascularization was significantly lower in the DCB vs. the control group ( $21 \%$ vs. $56 \%, \mathrm{p}=0.0005)$. DCBs also had lower binary restenosis $(17 \%$ vs. $54 \%$, $\mathrm{p}=0.04)$. DCBs had reduced target lesion revascularization over 5 years. No drug-related local vessel abnormalities were reported. ${ }^{56)}$

Another prospective study of 100 patients (82 limbs with claudication and 23 with CLI) underwent femoralpopliteal endovascular treatment with DCBs for restenosis (65 lesions) or de novo stenosis (111 lesions). The primary patency rate of de novo stenosis was higher at 6 months $(93 \%$ vs. $81 \%)$ and significantly $(\mathrm{p}=0.021)$ better than restenosis at 12 months ( $85 \%$ vs. $68 \%$ ). DCB angioplasty was effective for de novo femoral-popliteal lesions. Target lesion revascularization was significantly lower in de novo stenosis $(15 \%$ vs. $32 \%, p=0.021)$. DCB angioplasty for restenosis was inferior compared with de novo stenosis at 12 months. ${ }^{57)}$

\section{RANGER-SFA DCB (Boston Scientific)}

This study included early data on 105 patients from 10 sites in Europe. The 6-month follow-up data are encouraging. ${ }^{58)}$

Table 3 summarizes the outcomes of several drugcoated balloon trials in the SFA.

\section{Limitations of DCB}

One of the advantages of DCBs may also be one of their limitations. Currently, DCBs only utilize paclitaxel as the active drug. The development of devices with a variety of antiproliferative agents will allow the interventionist to customize therapy based on patient needs. For example, patients with CLI mostly need intervention that supports wound healing and salvages limbs. The use of cytotoxic agents, such as paclitaxel, may have an adverse impact on wound healing.

Furthermore, patients with PAD, particularly those with CLI, often present with calcified plaque. Calcified plaque is difficult to treat and is often associated with poor pro-

Table 3 Drug-coated balloon trials in the superficial femoral artery

\begin{tabular}{|c|c|c|c|c|c|}
\hline Trial & Design & $\begin{array}{l}\text { Lesion length: } \\
\text { DCB vs. control (mm) }\end{array}$ & $\begin{array}{l}\text { CTO lesion: } \\
\text { DCB vs. control }\end{array}$ & $\begin{array}{l}\text { Outcomes: } \\
\text { DCB vs. control }\end{array}$ & Other comments \\
\hline FemPac (2008) & $\begin{array}{c}\text { RCT: } \\
\text { DCB }(n=45) \text { vs. PTA }(n=42)\end{array}$ & $\begin{array}{l}\text { Median length: } \\
\quad 40 \text { vs. } 47 \\
(p=0.45)\end{array}$ & $\begin{array}{c}13 \% \text { vs. } 19 \% \\
(p=0.056)\end{array}$ & $\begin{array}{l}\text { TLR: } 13 \% \text { vs. } 50 \%(p=0.001) \\
\text { Primary patency: } 78 \% \text { vs. } 46 \% \\
\text { at } 24 \text { months }(p=0.001)\end{array}$ & $\begin{array}{l}66 \% \text { de novo lesions; } \\
43 \% \text { TASC II C and D }\end{array}$ \\
\hline THUNDER (2008) & $\begin{array}{c}\text { RCT: } \\
\text { DCB }(n=48) \text { vs. PTA+ paclitaxel } \\
\text { contrast }(n=52) \text { vs. PTA }(n=54)\end{array}$ & $\begin{array}{c}74 \pm 65 \text { vs. } 74 \pm 67 \\
\quad(p=0.73)\end{array}$ & $\begin{array}{c}14 \% \text { vs. } 14 \% \\
(p=1.0)\end{array}$ & $\begin{array}{l}\text { TLR: } 40 \% \text { vs. } 52 \% \text { at } 24 \text { months } \\
\qquad(p<0.001)\end{array}$ & $\begin{array}{l}\text { TLR similar for } \\
\text { paclitaxel contrast vs. PTA } \\
\text { at all time periods }\end{array}$ \\
\hline PACIFIER (2012) & $\begin{array}{c}\text { RCT: } \\
\text { DCB }(n=41) \text { vs. PTA }(n=44)\end{array}$ & $70 \pm 53$ vs. $66 \pm 55$ & $23 \%$ vs. $38 \%$ & $\begin{array}{l}\text { TLR: } 7 \% \text { vs. } 28 \% \text { at } 12 \text { months } \\
\qquad p=0.02\end{array}$ & $96 \%$ Rutherford $\leq 3$ \\
\hline BIOLUX P-I (2013) & $\begin{array}{c}\text { RCT: } \\
\text { DCB }(n=30) \text { vs. PTA }(n=30)\end{array}$ & $\begin{array}{l}51 \pm 47 \text { vs. } 69 \pm 57 \\
\quad(p=0.307)\end{array}$ & - & $\begin{array}{l}\text { TLR: } 13 \% \text { vs. } 42 \% \text { at } 12 \text { months } \\
\qquad(p=0.064)\end{array}$ & $\begin{array}{l}\text { As-treated } 12 \text { months } \\
\text { TLR: } 16 \% \text { vs. } 53 \%(p=0.020)\end{array}$ \\
\hline LEVANT I (2014) & $\begin{array}{c}\text { RCT: } \\
\text { DCB }(n=49) \text { vs. PTA }(n=52)\end{array}$ & $\begin{array}{c}81 \pm 37 \text { vs. } 80 \pm 38 \\
\quad(p=0.89)\end{array}$ & $\begin{array}{l}41 \% \text { vs. } 42 \% \\
\quad(p=0.88)\end{array}$ & $\begin{array}{c}\text { TLR: } 36 \% \text { vs. } 49 \%(p=0.23) \\
\text { Primary patency: } 57 \% \text { vs. } 40 \% \\
\text { at } 24 \text { months }\end{array}$ & 8 DCB failed to deploy \\
\hline
\end{tabular}

RCT: randomized controlled trial; FemPac: femoral paclitaxel; CTO: chronic total occlusion; THUNDER: local taxane with short exposure for reduction of restenosis in distal arteries; PACIFIER: paclitaxel-coated balloons reduce restenosis after femoropopliteal angioplasty; BIOLUX P-I: a prospective, multicenter, randomized controlled, first in man study to assess the safety and performance of the Passeo-18 lux paclitaxel-releasing PTA balloon catheter vs. the uncoated Passeo 18 balloon catheter in patients with stenosis and occlusion of the femoropopliteal arteries; LEVANT I: Lutonix paclitaxel-coated balloon for the prevention of femoropopliteal restenosis 
cedural and long-term success. Fanelli et al. found that patients with an increased calcific plaque burden had limited therapeutic benefit from DCBs. ${ }^{59)}$ This study showed that calcium, particularly in the media, represents a barrier for drug uptake. ${ }^{59)}$ Preparing the vessel with atherectomy before using DCBs is a strategy that can potentially improve the therapeutic effect of DCBs in calcified lesions. Cioppa et al. reported the results of a study to illustrate the safety and efficacy of using a combination of directional atherectomy with DCBs in treating calcific femoropopliteal lesions. The primary patency rate at 12 months was reported to be $90 \%$ (27/30), with a limb salvage rate of $100 \%{ }^{60)}$ More recently, the DEFINITIVE AR study was designed to evaluate the effects of directional atherectomy plus DCB therapy compared with DCB therapy alone. This multicenter pilot study evaluated 121 patients at 10 sites. At 12 months, the directional atherectomy plus DCB strategy illustrated a trend of improved patency $(82 \%$ vs. $72 \%)$. Patients with long lesions and severely calcified lesions derived the most benefit from this approach $191 \%$ vs. $69 \%$ patency in lesions $>10 \mathrm{~cm}$ and $58 \%$ vs. $43 \%$ patency in severe calcified lesions). ${ }^{611}$

\section{Drug-Coated Stents}

\section{SIROCCO I and II trials}

Sirolimus-eluting stents (Cordis Smart nitinol self-expanding stent for the treatment of SFA disease) were compared with bare metal stents. No difference was found in in-stent restenosis at 6 months and 2 years. ${ }^{62,63)}$

Later studies with Zilver PTX (paclitaxel) stents (Cook Medical, Bloomington, IN, USA) proved its safety and ef- ficacy, and it was superior to PTA with provisional stent placement. ${ }^{64)}$ In a study by Dake et al. with the Zilver PTX stent, 474 patients were randomized to primary DES or PTA with provisional stents with subsequent secondary randomization to bare metal stents or DES for patients requiring provisional stents. The event-free survival at 1 year was $90 \%$ for primary DES vs. $83 \%$ for the control $\operatorname{arm}(\mathrm{p}=0.004)$. The primary patency rate at 1 year was $83 \%$ and $33 \%$ for DES and PTA alone, respectively. ${ }^{64)}$

Later studies with Zilver PTX stents reported a primary patency rate of $83.1 \%$ and $65.3 \%$ for DES and PTA, respectively, excluding acute PTA failure $(\mathrm{p}<0.001)$. Data still support the safety and efficacy of drug-coated stent (DCS) at 2 years. ${ }^{65)}$ In a larger prospective registry of 787 patients, the 2-year freedom from target lesion revascularization with primary DES placement was $80.5 \%$ in the single-arm study. ${ }^{66)}$ The Zilver PTX stent was also examined for the treatment of in-stent restenosis. In patients with a mean lesion length of $13 \mathrm{~cm}$ (31\% total occlusions), the procedural success rate was $98 \%$, and the primary patency rate at 1 year was $79 \%$, and the freedom from target lesion revascularization at 2 years was $61 \% .{ }^{67)}$ Dual antiplatelet therapy is recommended for 6 months with the use of the Zilver PTX. Later 5-year data showed that DCS (paclitaxel) had better patency rates than standard PTA ( $66.4 \%$ for lesion $65 \pm 40 \mathrm{~mm}$ in length) and better freedom from target lesion revascularization $(85 \%) .{ }^{68)}$

\section{Eluvia DES (Boston Scientific)}

This is a prospective, single-arm, MAJESTIC clinical trial of the treatment of femoral-popliteal lesions up to $110 \mathrm{~mm}$ in length (paclitaxel coating). The study enrolled

Table 4 Drug-coated stent trials in the superficial femoral artery

\begin{tabular}{|c|c|c|c|c|c|}
\hline Trial & Design & $\begin{array}{l}\text { Lesion length: } \\
\text { DCS vs. control }(\mathrm{mm})\end{array}$ & $\begin{array}{l}\text { CTO lesion: } \\
\text { DCS vs. control }\end{array}$ & Outcomes DCS vs. control & Other comments \\
\hline SIROCCO (2006) & $\begin{array}{c}\text { RCT: } \\
\text { DCS }(n=47) \text { vs. } \\
\text { BMS }(n=46)\end{array}$ & $85 \pm 44$ vs. $81 \pm 52$ & $69 \%$ vs. $57 \%$ & $\begin{array}{c}\text { TLR: } 6 \% \text { vs. } 13 \%(p=0.30) \\
\text { restenosis: } 23 \% \text { vs. } 21 \% \\
\text { at } 24 \text { months }\end{array}$ & $\begin{array}{l}\text { DAPT: } 3-4 \text { months; } \\
85 \% \text { received } \leq 2 \text { stents; } \\
100 \% \text { Rutherford } \leq 4\end{array}$ \\
\hline STRIDES (2011) & $\begin{array}{l}\text { Single-arm trial: } \\
\text { DCS }(n=104)\end{array}$ & $90 \pm 43$ & $45 \%$ & $\begin{array}{c}\text { TLR: } 30 \% \text {; } \\
\text { primary patency: } 55 \% \text { at } 12 \text { months }\end{array}$ & $\begin{array}{c}\text { DAPT: } 6 \text { months; } \\
94 \% \text { received } \leq \text { stents; } \\
87 \% \text { TASC II A and B }\end{array}$ \\
\hline Zilver-PTX (2013) & $\begin{array}{c}\text { DCS }(n=236) \text { vs. } \\
\text { PTA }(n=238), \\
\text { RCT optimal PTA }(n=118) \\
\text { provisional BMS }(n=59) \\
\text { provisional DCS }(n=61)\end{array}$ & $\begin{array}{c}67 \pm 39 \text { vs. } 63 \pm 41 \\
\quad(p=0.31)\end{array}$ & $\begin{array}{c}33 \% \text { vs. } 27 \% \\
\quad(p=0.2)\end{array}$ & $\begin{array}{l}\text { a Primary patency: } 75 \% \text { vs. } 27 \% \\
\text { at } 24 \text { months ( } p<0.01 \text { ); } \\
\text { bPrimary patency: } 83 \% \text { vs. } 64 \% \\
\text { at } 24 \text { months ( } p<0.01 \text { ); } \\
{ }^{\text {c } T L R: ~} 17 \% \text { vs. } 31 \% \text { at } 48 \text { months } \\
\text { ( } p<0.01 \text { ); } \\
\text { bPrimary patency: } 75 \% \text { vs. } 58 \% \\
\text { at } 48 \text { months ( } p=0.04 \text { ); } \\
\text { TLR: } 20 \% \text { at } 24 \text { months }\end{array}$ & \\
\hline Zilver PTX (2013) & $\begin{array}{l}\text { Single-arm trial: } \\
\text { DCS }(n=787)\end{array}$ & $99.5 \pm 82.1$ & $38 \%$ & $\begin{array}{l}\text { TLR: } 19.5 \% \\
\text { at } 24 \text { months }\end{array}$ & $\begin{array}{c}\text { Study included } 13 \% \text { ISR } \\
\text { lesions, compared with } 0 \text { in RCT }\end{array}$ \\
\hline
\end{tabular}

DCS: drug-coated stent; CTO: chronic total occlusion; DAPT: dual antiplatelet therapy; BMS: bare metal stent; SIROCCO: Sirolimus-coated Cordis self-expandable stent; STRIDES: superficial femoral artery treatment with drug-eluting stents 


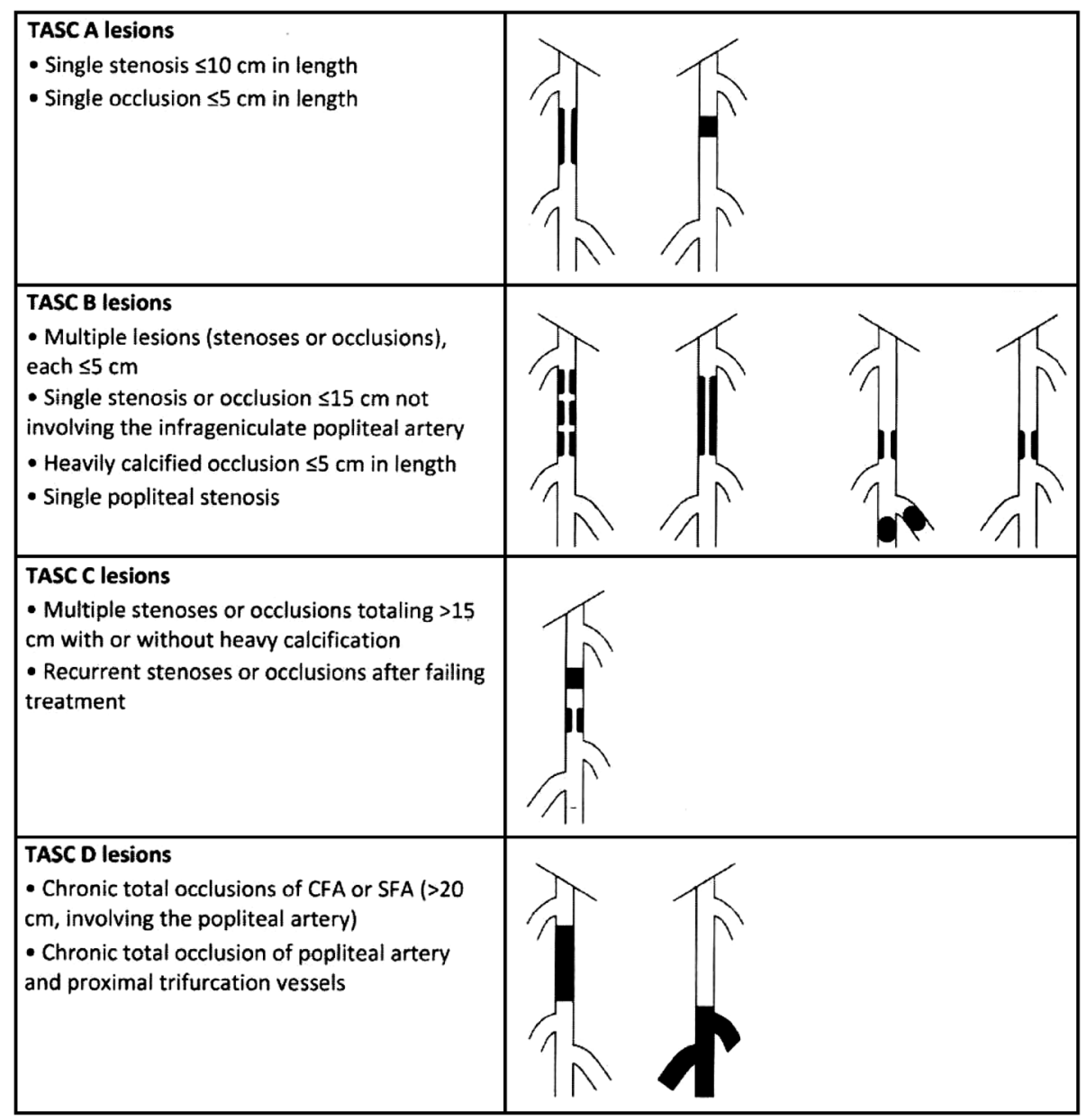

Fig. 2 Treatment of choice for femoropopliteal disease: endovascular vs. open (according to TASC classification).

57 patients, with a mean lesion length of $71 \pm 28 \mathrm{~mm}$, in Europe, Australia, and New Zealand. Severe calcification and occlusion were noted in $65 \%$ and $46 \%$, respectively. The freedom from target lesion revascularization at 24 months was $93 \%$. No major amputations and no stent fractures occurred. ${ }^{69)}$ Table 4 summarizes the outcomes of drug-coated stent trials in the SFA.

We have used approximately 156 SFA/popliteal DCBs (Lutonix) since 2012 and 50 DCS (Zilver PTX) with encouraging early results.

\section{DCB vs. DES for SFA Interventions}

Procedural and anatomical considerations play a major role in the treatment of choice. Lesion length, type of recanalization (subintimal vs. intraluminal), degree of calcification, and lesion site (ostial, popliteal) should all be considered when choosing the primary strategy. As a general rule, one must avoid stenting when unnecessary due to the possibility worse stent restenosis.

Similar outcomes after DCBs and DES in long femo- ropopliteal lesions (lesion length, $194 \pm 86 \mathrm{~mm}$ and 195 $64 \mathrm{~mm}$, respectively) were found in a recently published analysis. ${ }^{70)}$ The primary patency rate was promising $(76 \%$ and $70 \%$, respectively), and the freedom from clinically driven target lesion revascularization $(84 \%$ and $81 \%$, respectively) was high after DCB and DES at 12-month follow-up. Overall, both modalities work well in longer and shorter lesions.

Without a doubt, one should try to avoid leaving a prosthetic behind. Using DCB for TASC B, C, or D lesion upon first presentation and also on restenotic lesions, as well as for in-stent restenosis in the femoropopliteal area, is generally recommended. If significant flow-limiting dissection remains, use of DES as a kind of bailout stent is appropriate.

\section{Brachytherapy}

Another modality used to treat restenosis after PTA is brachytherapy. It uses ionizing radiation to inhibit cellular proliferation with the aim of preventing the component of 
Table 5 Initial revascularization strategy in critical limb ischemia and diabetes

\begin{tabular}{lll}
\hline & \multicolumn{1}{c}{ Bypass favored } & Endovascular treatment favored \\
\hline Life expectancy & $\geq 2$ years & Limited \\
Surgical risk (30-day mortality) & Average $(<5 \%)$ & High \\
Severity of ischemia & Major tissue loss & Minor tissue loss: ulcer \\
Vein availability & GSV or good alternate & Inadequate \\
Anatomy & Multilevel, TASC C/D & Single level, TASC A-C \\
\hline
\end{tabular}

restenosis mediated by the uncontrolled proliferation of smooth muscle cells. The PARIS study demonstrated the safety and feasibility of gamma radiation after balloon angioplasty. ${ }^{71)}$ The use of brachytherapy for PAD was supported by a small, randomized trial of 113 patients that compared PTA alone with PTA and brachytherapy for both de novo and recurrent femoropopliteal lesions. Restenosis rates of $28 \%$ in the PTA-brachytherapy group were compared with $53.7 \%$ in the PTA-alone group $(\mathrm{p}<0.05) .{ }^{72)}$ A recent review of eight trials with 1,090 participants showed that target lesion revascularization was reduced in patients treated with brachytherapy over PTA alone at 6 months; however, no significant difference was found in reintervention at $12-24$ months. ${ }^{73)}$ Additional research is needed in this field.

\section{Cryoplasty}

Cryoplasty is a combination of a low-pressure balloon angioplasty combined with cryotherapy, briefly cooling the vessel to $-10^{\circ} \mathrm{C}$. This may induce smooth cell apoptosis. ${ }^{74}$ The data for cryoplasty are conflicting, and some studies have revealed no benefit or even a lack of efficacy compared with PTA. The COLD study was associated with lower anatomic success compared with conventional PTA and a nonstatistically significant difference in primary patency at 9 months. ${ }^{75)}$ Long-term results from a single-center controlled trial of 50 patients with diabetes and femoropopliteal disease comparing cryoplasty to PTA also found lower primary patency and higher clinically driven reintervention in the cryoplasty group. ${ }^{76}$ )

Whether cryoplasty is truly an effective and acceptable alternative to conventional PTA remains unclear because the data are mixed.

\section{Choice of Treatment for Femoral-Popliteal Disease-Endovascular vs. Open}

Based on previous data, most authorities recommend endovascular therapy first for TASC A, B, and C lesions and surgical bypass of TASC D lesions, except in high surgical risk patients (see Fig. 2 and Table 5). Bypass surgery is generally recommended for complex, extensive, superficial femoral/popliteal artery lesions for patients with more than a 2-year life expectancy. This decision is very critical, and economic costs must also be considered. The rate of repeat procedures at 24 months was $36 \%, 27 \%, 19 \%$, and $18 \%$ for plain balloons, bare metal stents, DCSs, and DEBs, respectively. ${ }^{77)}$

Antoniou et al. supported by recent meta-analysis that included 10 published randomized controlled trials, only one of which was considered high quality, suggested an endovascular-first strategy, particularly in patients with a limited life expectancy. ${ }^{78)}$

\section{Conclusion}

Based on a nearly universal procedure success rate, low morbidity and mortality, and improving patency rates with newer devices, endovascular treatment is the recommended treatment of choice, particularly with TASC A-C lesions; although open surgical bypass with ASV grafts is a durable choice in low-risk patients. However, until more well-designed randomized trials are completed, physicians should rely on their best clinical judgment. Two new studies, BEST-CLI and BASIL-2 and -3, are enrolling patients to further compare open surgery vs. endovascular treatment for selected patients with CLI.

\section{Disclosure Statement}

I have no conflicts of interest.

\section{References}

1) Fowkes FG, Rudan D, Rudan I, et al. Comparison of global estimates of prevalence and risk factors for peripheral artery disease in 2000 and 2010: a systematic review and analysis. Lancet 2013; 382: 1329-40.

2) Mahoney EM, Wang K, Keo HH, et al. Vascular hospitalization rates and costs in patients with peripheral artery disease in the United States. Circ Cardiovasc Qual Outcomes 2010; 3: 642-51.

3) Norgren L, Hiatt WR, Dormandy JA, et al. Inter-society consensus for the management of peripheral arterial disease (TASC II). Eur J Vasc Endovasc Surg 2007; 33 Suppl 1: S175 .

4) Barani J, Nilsson JA, Mattiasson I, et al. Inflammatory mediators are associated with 1-year mortality in critical limb ischemia. J Vasc Surg 2005; 42: 75-80. 
5) Conte MS. Diabetic revascularization: endovascular versus open bypass-do we have the answer? Semin Vasc Surg 2012; 25: 108-14.

6) Van der Slegt J, Steunenberg SL, Donker JMW, et al. The current position of precuffed expanded polytetrafluorethylene bypass grafts in peripheral vascular surgery. J Vasc Surg 2014; 60: 120-8.

7) Iida O, Nakamura M, Yamauchi Y, et al. Endovascular treatment for infrainguinal vessels in patients with critical limb ischemia: OLIVE Registry, a prospective, multicenter study in Japan with 12-month follow-up. Circ Cardiovasc Interv 2013; 6: 68-76.

8) Lepäntalo M, Laurila K, Roth WD, et al. PTFE bypass or thrupass for superficial femoral artery occlusion? A randomised controlled trial. Eur J Vasc Endovasc Surg 2009; 37 : 578-84.

9) Jones WS, Dolor RJ, Hasselblad V, et al. Comparative effectiveness of endovascular and surgical revascularization for patients with peripheral artery disease and critical limb ischemia: systematic review of revascularization in critical limb ischemia. Am Heart J 2014; 167: 489-98.

10) Rooke TW, Hirsch AT, Misra S, et al. 2011 ACCF/AHA focused update of the guideline for the management of patients with peripheral artery disease (updating the 2005 guideline): a report of the American College of Cardiology Foundation/ American Heart Association Task Force on Practice Guidelines: developed in collaboration with the Society for Cardiovascular Angiography and Interventions, Society of Interventional Radiology, Society for Vascular Medicine, and Society for Vascular Surgery. J Vasc Surg 2011; 54: 32-58.

11) van der Zaag ES, Legemate DA, Prins MH, et al. Angioplasty or bypass for superficial femoral artery disease? A randomised controlled trial. Eur J Vasc Endovasc Surg 2004; 28 : 132-7.

12) McQuade K, Gable D, Hohman S, et al. Randomized comparison of ePTFE/nitinol self-expanding stent graft vs prosthetic femoral-popliteal bypass in the treatment of superficial femoral artery occlusive disease. J Vasc Surg 2009; 49: 109-15, 116.e1-9; discussion, 116.

13) Conte MS, Geraghty PJ, Bradbury AW, et al. Suggested objective performance goals and clinical trial design for evaluating catheter-based treatment of critical limb ischemia. J Vasc Surg 2009; 50: 1462-73, 3.

14) Singh N, Sidawy AN, Dezee KJ, et al. Factors associated with early failure of infrainguinal lower extremity arterial bypass. J Vasc Surg 2008; 47: 556-61.

15) Akbari CM, Pomposelli FB Jr, Gibbons GW, et al. Lower extremity revascularization in diabetes: late observations. Arch Surg 2000; 135: 452-6.

16) Best endovascular vs. Best surgical therapy in patients with critical limb ischemia (BEST-CLI). Available from: https:// clinicaltrials.gov/ct2/show/NCT02060630

17) Siracuse JJ, Giles KA, Pomposelli FB, et al. Results of primary bypass versus primary angioplasty/stent for intermittent claudication due to superficial femoral artery occlusive disease. J Vasc Surg 2012; 55: 1001-7.

18) Dosluoglu HH, Cherr GS, Lall P, et al. Stenting vs. above knee polytetrafluoroethylene bypass for TransAtlantic InterSociety Consensus-II C and D superficial femoral artery disease. J Vasc Surg 2008; 48: 1166-74.
19) Kudo T, Chandra FA, Ahn SS. The effectiveness of percutaneous transluminal angioplasty for the treatment of critical limb ischemia: a 10-year experience. J Vasc Surg 2005; 41 : 423-35; discussion, 435.

20) Romiti M, Albers M, Brochado-Neto FC, et al. Metaanalysis of infrapopliteal angioplasty for chronic critical limb ischemia. J Vasc Surg 2008; 47: 975-81.e1.

21) Clark TW, Groffsky JL, Soulen MC. Predictors of long-term patency after femoropopliteal angioplasty: results from the STAR registry. J Vasc Interv Radiol 2001; 12: 23-33.

22) Clair DG, Sarac TP, Titus JM. Percutaneous angioplasty with and without stenting for lower extremity occlusive disease. In: Stanley JC, Veith FJ, Wakefield TW eds. Current Therapy in Vascular and Endovascular Surgery, 5th edition. Philadelphia: Elsevier Saunders, 2014: 537-41.

23) Met R, Van Lienden KP, Koeleman MJ, et al. Subintimal angioplasty for peripheral arterial occlusive disease: a systematic review. Cardiovasc Intervent Radiol 2008; 31: 687-97.

24) Laird JR, Katzen BT, Scheinert D, et al. Nitinol stent implantation versus balloon angioplasty for lesions in the superficial femoral artery and proximal popliteal artery: twelve-month results from the RESILIENT randomized trial. Circ Cardiovasc Interv 2010; 3: 267-76.

25) Laird JR, Katzen BT, Scheinert D, et al. Nitinol stent implantation vs. balloon angioplasty for lesions in the superficial femoral and proximal popliteal arteries of patients with claudication: three-year follow-up from the RESILIENT randomized trial. J Endovasc Ther 2012; 19: 1-9.

26) Schillinger M, Sabeti S, Loewe C, et al. Balloon angioplasty versus implantation of nitinol stents in the superficial femoral artery. N Engl J Med 2006; 354: 1879-88.

27) Schillinger M, Sabeti S, Dick P, et al. Sustained benefit at 2 years of primary femoropopliteal stenting compared with balloon angioplasty with optional stenting. Circulation 2007; 115: 2745-9.

28) Brescia AA, Wickers BM, Correa JC, et al. Stenting of femoropopliteal lesions using interwoven nitinol stents. J Vasc Surg 2015; 61: 1472-8.

29) Montero-Baker M, Ziomek GJ, Leon L, et al. Analysis of endovascular therapy for femoropopliteal disease with the Supera stent. J Vasc Surg 2016; 64: 1002-8.

30) Laird J. Novel nitinol stent for long lesions in the superficial femoral artery and proximal popliteal artery: 24-month results from the TIGRIS randomized trial. Vascular Interventional Advances (VIVA) Meeting, Las Vegas, Nevada, USA, September 19-21, 2016.

31) Scheinert D, Scheinert S, Sax J, et al. Prevalence and clinical impact of stent fractures after femoropopliteal stenting. J Am Coll Cardiol 2005; 45: 312-5.

32) Amighi J, Schillinger M, Dick P, et al. De novo superficial femoropopliteal artery lesions: peripheral cutting balloon angioplasty and restenosis rates-randomized controlled trial. Radiology 2008; 247: 267-72.

33) Vikram R, Ross RA, Bhat R, et al. Cutting balloon angioplasty versus standard balloon angioplasty for failing infrainguinal vein grafts: comparative study of short- and midterm primary patency rates. Cardiovasc Intervent Radiol 2007; 30: 607-10.

34) Schillinger M, Minar E. Percutaneous treatment of peripheral artery disease: novel techniques. Circulation 2012; 126: 
2433-40.

35) Garcia LA, Lyden SP. Atherectomy for infrainguinal peripheral artery disease. J Endovasc Ther 2009; 16 Suppl 2: II10515.

36) Kandzari DE, Kiesz RS, Allie D, et al. Procedural and clinical outcomes with catheter-based plaque excision in critical limb ischemia. J Endovasc Ther 2006; 13: 12-22.

37) Ramaiah V, Gammon R, Kiesz S, et al. Midterm outcomes from the TALON registry: treating peripherals with SilverHawk: outcomes collection. J Endovasc Ther 2006; 13: 592-602.

38) Zeller T, Rastan A, Sixt S, et al. Long-term results after directional atherectomy of femoro-popliteal lesions. J Am Coll Cardiol 2006; 48: 1573-8.

39) McKinsey JF, Goldstein L, Khan HU, et al. Novel treatment of patients with lower extremity ischemia: use of percutaneous atherectomy in 579 lesions. Ann Surg 2008; 248: 51928.

40) Scheinert D, Laird JR Jr, Schröder M, et al. Excimer laserassisted recanalization of long, chronic superficial femoral artery occlusions. J Endovasc Ther 2001; 8: 156-66.

41) Laird JR, Zeller T, Gray BH, et al. Limb salvage following laser-assisted angioplasty for critical limb ischemia: results of the LACI multicenter trial. J Endovasc Ther 2006; 13: 111.

42) Dippel EJ, Makam P, Kovach R, et al. Randomized controlled study of excimer laser atherectomy for treatment of femoropopliteal in-stent restenosis: initial results from the EXCITE ISR trial (EXCImer Laser Randomized Controlled Study for Treatment of FemoropopliTEal In-Stent Restenosis). JACC Cardiovasc Interv 2015; 81 Pt A: 92-101.

43) Lammer J, Zeller T, Hausegger KA, et al. Heparin-bonded covered stents versus bare-metal stents for complex femoropopliteal artery lesions: the randomized VIASTAR trial (Viabahn endoprosthesis with PROPATEN bioactive surface [VIA] versus bare nitinol stent in the treatment of long lesions in superficial femoral artery occlusive disease). J Am Coll Cardiol 2013; 62: 1320-7.

44) Saxon RR, Chervu A, Jones PA, et al. Heparin-bonded, expanded polytetrafluoroethylene-lined stent graft in the treatment of femoropopliteal artery disease: 1-year results of the VIPER (Viabahn Endoprosthesis with Heparin Bioactive Surface in the Treatment of Superficial Femoral Artery Obstructive Disease) trial. J Vasc Interv Radiol 2013; 24 : 165-73; quiz, 174.

45) Lammer J, Zeller T, Hausegger KA, et al. Sustained benefit at 2 years for covered stents versus bare-metal stents in long SFA lesions: the VIASTAR trial. Cardiovasc Intervent Radiol 2015; 38: 25-32.

46) Ansel G, et al. ClinicalTrials.gov [Internet]. 2012 National Library of Medicine (US), Bethesda, MD. http://www.clinical trials.gov/ct2/show/results/NCT00228384? sect $=$ X6015.

47) Virmani R. Understanding the science behind the outcomes: sustained drug, sustained benefit. Charring Cross 2016, London, United Kingdom, April 26-29, 2016.

48) Werk M, Langner S, Reinkensmeier B, et al. Inhibition of restenosis in femoropopliteal arteries paclitaxel-coated versus uncoated balloon: femoral paclitaxel randomized pilot trial. Circulation 2008; 118: 1358-65.

49) Tepe G, Zeller T, Albrecht T, et al. Local delivery of pacli- taxel to inhibit restenosis during angioplasty of the leg. $\mathrm{N}$ Engl J Med 2008; 358: 689-99.

50) Werk M, Albrecht T, Meyer DR, et al. Paclitaxel-coated balloons reduce restenosis after femoro-popliteal angioplasty evidence from the randomized PACIFIER trial. Circ Cardiovasc Interv 2012; 5: 831-40.

51) Scheinert D, Duda S, Zeller T, et al. The LEVANT I (Lutonix paclitaxel-coated balloon for the prevention of femoropopliteal restenosis) trial for femoropopliteal revascularization: first-in-human randomized trial of low-dose drug-coated balloon versus uncoated balloon angioplasty. JACC Cardiovasc Interv 2014; 7: 10-9.

52) Zeller T, Baumgartner I, Scheinert D, et al. Drug-eluting balloon versus standard balloon angioplasty for infrapopliteal arterial revascularization in critical limb ischemia: 12-month results from the IN.PACT DEEP randomized trial. J Am Coll Cardiol 2014; 64: 1568-76.

53) Tepe G, Laird J, Schneider P, et al. Drug-coated balloon versus standard percutaneous transluminal angioplasty for the treatment of superficial femoral and popliteal peripheral artery disease: 12-month results from the IN.PACT SFA randomized trial. Circulation 2015; 131: 495-502.

54) Micari A, Ciopa A, Vadala G, et al. Clinical evaluation of a paclitaxel-eluting balloon for treatment of femoropopliteal arterial disease: 12-month results from a multicenter Italian registry. JACC Cardiovasc Interv 2012; 5: 331-8.

55) Jaff M. Drug-coated balloon treatment for patients with intermittent claudication: insights from the IN.PACT global full clinical cohort. Vascular InterVentional Advances (VIVA) 2016, Las Vegas, Nevada, USA, September 19-22, 2016.

56) Tepe G, Schnorr B, Albrecht T, et al. Angioplasty of femoralpopliteal arteries with drug-coated balloons: 5-year followup of the THUNDER trial. JACC Cardiovasc Interv 2015; 8 1 Pt A: 102-8.

57) Herten M, Torsello GB, Schonefeld E, et al. Drug-eluting balloons for femoropopliteal lesions show better performance in de novo stenosis or occlusion than in restenosis. J Vasc Surg 2015; 61: 394-9.

58) Von Bilderling P. An overview of trials and breaking data from the RANGER ${ }^{\mathrm{TM}}$ drug-coated balloon clinical programme. Cardiovascular and Interventional Radiological Society of Europe (CIRSE), Barcelona, Spain, September 10-14, 2016.

59) Fanelli F, Cannavele A, Gazzetti M, et al. Calcium burden assessment and impact on drug-eluting balloons in peripheral arterial disease. Cardiovasc Intervent Radiol 2014; 37: 898907.

60) Cioppa A, Stabile E, Popusoi G, et al. Combined treatment of heavy calcified femoro-popliteal lesions using directional atherectomy and a paclitaxel coated balloon: one-year single centre clinical results. Cardiovasc Revasc Med 2012; 13 : 219-23.

61) Zeller T. DEFINITIVE AR: a pilot study of antirestenosis treatment. Presented at Vascular InterVentional Advances (VIVA), Las Vegas, NV, USA, November 4-7, 2014.

62) Duda SH, Bosiers M, Lammer J, et al. Sirolimus-eluting versus bare nitinol stent for obstruction superficial femoral artery disease: the SIROCCO II trial. J Vasc Interv Radiol 2005; 16: 331-8. 
63) Duda SH, Bosiers M, Lammer J, et al. Drug-eluting and bare nitinol stents for the treatment of atherosclerotic lesions in the superficial femoral artery: long-term results from the SIROCCO trial. J Endovasc Ther 2006; 13: 701-10.

64) Dake MD, Ansel GM, Jaff MR, et al. Sustained safety and effectiveness of paclitaxel-eluting stents for femoropopliteal lesions: 2-year follow-up from the Zilver PTX randomized and single-arm clinical studies. J Am Coll Cardiol 2013; 61: 2417-27.

65) Dake MD, Scheinert D, Tepe G, et al. Nitinol stents with polymer-free paclitaxel coating for lesions in the superficial femoral and popliteal arteries above the knee: twelve-month safety and effectiveness results from the ZILVER PTX singlearm clinical study. J Endovasc Ther 2011; 18: 613-23.

66) Dake MD, Ansel GM, Jaff MR, et al. Sustained safety and effectiveness of paclitaxel-eluting stents for femoropopliteal lesions: 2-year follow-up from the Zilver PTX randomized and single-arm clinical studies. J Am Coll Cardiol 2013; 61: 2417-27.

67) Zeller T, Dake MD, Tepe G, et al. Treatment of femoropopliteal in-stent restenosis with paclitaxel-eluting stents. JACC Cardiovasc Interv 2013; 6: 274-81.

68) Dake MD, Ansel GM, Jaff MR, et al. Durable clinical effectiveness with PES in femoropopliteal artery 5-year results of the Zilver PTX randomized clinical trial. Circulation 2016; 133: $1472-83$.

69) Muller-Hulsbeck S. ELUVIA ${ }^{\mathrm{TM}}$ drug-eluting stent: from preclinical foundations to MAJESTIC FIM and IMPERIAL global trial. CIRSE 2016, Barcelona, Spain, September 11-13, 2016.

70) Zeller T, Rastan A, Macharzina R, et al. Drug-coated balloons vs. drug-eluting stents for treatment of long femoropopliteal lesions. J Endovasc Ther 2014; 21: 359-68.
71) Wakeman R, Laird JR, Jurkovitz CT, et al. Intravascular radiation therapy after balloon angioplasty of narrowed femoropopliteal arteries to prevent restenosis: results of the PARIS feasibility clinical trial. J Vasc Interv Radiol 2001; 12: 915-21.

72) Minar E, Pokrajac B, Maca T, et al. Endovascular brachytherapy for prophylaxis of restenosis after femoropopliteal angioplasty: results of a prospective randomized study. Circulation 2000; 102: 2694-9.

73) Andras A, Hansrani M, Stewart M, et al. Intravascular brachytherapy for peripheral vascular disease. Cochrane Database Syst Rev 2014; 1: CD003504.

74) Davies MG, Anaya-Ayala JE. Endovascular techniques in limb salvage: cutting, cryo, brachy, and drug-eluting balloons. Methodist DeBakey Cardiovasc J 2013; 9: 69-72.

75) Jahnke T, Mueller-Huelsbeck S, Charalambous N, et al. Prospective, randomized single-center trial to compare cryoplasty versus conventional angioplasty in the popliteal artery: midterm results of the COLD study. J Vasc Interv Radiol 2010; 21: 186-94.

76) Spiliopoulos S, Katsanos Karnabatidis D, et al. Cryoplasty versus conventional balloon angioplasty of the femoropopliteal artery in diabetic patients: long-term results from a prospective randomized single-center controlled trial. Cardiovasc Intervent Radiol 2010; 33: 929-38.

77) Katsanos K, Geisler BP, Garner AM, et al. Economic analysis of endovascular drug-eluting treatments for femoropopliteal artery disease in the UK. BMJ Open 2016; e011245. DOI: 10.1136/bmjopen-2016-011245

78) Antoniou GA, Chalmers N, Georgiadis GS, et al. A metaanalysis of endovascular versus surgical reconstruction of femoropopliteal arterial disease. J Vasc Surg 2013; 57: 24253. 